\title{
Chlorination disinfection byproducts (DBPs): a review of Malaysian drinking water policy and consumers' perception
}

\begin{abstract}
Chlorine is used by water treatment plants (WTPs) in Malaysia to disinfect water from harmful microorganisms. However, chlorine can react with natural and organic materials and lead to the formation of disinfection byproducts (DBPs). DBPs are harmful to human health when exposed in sufficient quantities over a period of time. The objectives of this study are to examine Malaysian drinking water policy in relation to DBPs in the light of international guidelines especially the World Health Organization Guidelines for Drinking-Water Quality 2011 (WHO Guidelines) and to do a preliminary study of consumersôperception on drinking water quality in Selangor. In order to achieve these objectives, a targeted document review, and key-informant interview with officers from the Ministry of Health and a survey of consumersôperception were conducted. The study found that Malaysia adopts more stringent standard values for certain DBPs than the WHO Guidelines, but not in terms of monitoring and strategies for reducing the by-products. The survey result showed that $91 \%$ of the respondents can tolerate minimal presences of DBPs, which have to comply to the regulations set by the Ministry of Health. Overall, $76 \%$ of the respondents were satisfied with the drinking water quality at home.
\end{abstract}

Keyword: Chlorination; Disinfection byproducts; Drinking water; Malaysian policy; Consumer perception 